\title{
Improving Student Success for Diverse Students Utilizing Competency-Based Education
}

\author{
Alton James \\ Western Governors University \\ alton.james@wgu.edu
}

\begin{abstract}
This research aims to conduct exploratory research on the myriad issues that traditionally underserved students face in average higher education settings and poses a potential curricula and pedagogical solution. Particularly within the humanities, subjectivity can sometimes be infused into the curricula and pedagogy, and student assessment; and may impact student examination scores and overall success. In assessing student work through competency-based education (CBE), underserved students can inject their own experiences into the learning environment. Such participation potentially yields significant learning experiences for the entire teaching-learning pipeline and everyone involved (student, teacher, and classmates). Essentially, the utilization of $\mathrm{CBE}$ can allow traditionally underserved students to experience their education at their own pace. CBE has the potential to more sufficiently tend to the holistic needs of the student as well.
\end{abstract}

Keywords: Competency-Based Education, Diverse Student Success, The Impostor Syndrome, Culturally Relevant Pedagogy

Addressing the unique needs of traditionally underserved, disenfranchised, and diverse students is a concern for many higher education institutions. While policies and programs center on the campus climate, student readiness, the necessity of remediation, provision of specific student services and professor/student ratio, there is little information in the literature regarding the introduction of culturally sensitive and appropriate instructional strategies and pedagogy. As debates proliferate around professorial tenure and academic freedom, emphases on curricula and instruction can be lost in the fray - particularly when using them as a vehicle to improve outcomes for underrepresented and underserved students. This article suggests the introduction and use of Competency-Based Education (CBE) as a means of combating subpar educational achievement and attainment for traditionally underserved/diverse populations.

The US Department of Education outlines the characteristics of CBE quite thoroughly in the following manner:

Transitioning away from seat time, in favor of a structure that creates flexibility, allows students to progress as they demonstrate mastery of academic content, regardless of time, place, or pace of learning. Competency-based strategies provide flexibility in the way that credit can be earned or awarded and provide students with personalized learning opportunities. These strategies include online and blended learning, dual enrollment and early college high schools, project-based and community-based learning, and credit recovery, among others. This type of learning leads to better student engagement because the content is relevant to each student and tailored to their unique needs. It also leads to

Cultural and Pedagogical Inquiry, Summer 2019, 11(2), pp. 67-77

ISSN 1916-3460 @ 2019 University of Alberta

http://ejournals.library.ualberta.ca/index.php/cpi/index 
better student outcomes because the pace of learning is customized to each student. By enabling students to master skills at their own pace, competency-based learning systems help to save both time and money. Depending on the strategy pursued, competency-based systems also create multiple pathways to graduation, make better use of technology, support new staffing patterns that utilize teacher skills and interests differently, take advantage of learning opportunities outside of school hours and walls, and help identify opportunities to target interventions to meet the specific learning needs of students. Each of these presents an opportunity to achieve greater efficiency and increase productivity. (US Department of Education, 2018)

While entities like the US Department of Education identify the over-arching ideas of $\mathrm{CBE}$, the notion of achieving educational competence requires further explanation.

Demonstrating that one has genuinely acquired the prescribed knowledge and skills, is inherently divorced from a singular set paradigm of assessments. Proving one's abilities potentially becomes more objective, if given the opportunity to showcase one's abilities in myriad types of examinations. Granted, that researchers have identified cultural biases in some educational assessments. Hartlage, Lucas, \& Godwin (1976), for example, found strongly skewed results in intelligence testing for general students and students with disabilities when culturally biased and unfair examinations were administered. (The experiments dated back to the 1970s). Accordingly, the effective use of CBE can potentially curb issues of assessment and pedagogical biases and provide improved opportunities for diverse and traditionally underserved students to realize success in their educational endeavors.

Furthermore, considering that traditionally underserved/diverse populations cope with major issues such as, economic hardship in college attendance, lack of academic preparedness, and psychological barriers such as the Impostor Syndrome, CBE potentially allows students to accelerate their learning while at the same time, reducing financial costs, utilizing practical knowledge, achieving competency through personal course pacing, and using culturally relevant course materials.

\section{Historical Overview}

\section{The Changing Context of Higher Education and Implications for Diverse Students}

Higher educational institutions were created to serve a homogenous, elite population. In contrast, the current college student demography does not fit the original model. In fact, Duderstadt \& Womack (2003) noted that a balance between standards of excellence and elitism must be achieved in contemporary higher education. Their research suggested that the contemporary college structure is not a wise social policy. So much so, that they advocated "The Learn Grant Act" which addresses issues of college access and affordability. Furthermore, they argued that a systemic investment in higher education must occur to prepare the American citizens for the new knowledge-based society, in the presence of a growing technological economy which is likely to change the method by which people function within the workforceparticularly, considering the important and pervasive roles of robotics, automation, and artificial intelligence.

In light of this changing historical context, it is important to recall the evolution of higher education as it pertains to its purpose, as well as its connections to society, economics, and 
market forces, writ large. Higher education has historically been designed to serve a rich American aristocracy (Thelin, 2004). Throughout the colonial era and prior to the Roaring 1920s, colleges and universities were designed to enhance the erudition and elite status of Anglo-Saxon men, in particular. While these college-goers served the wealth building agendas of captains of industry, the majority of the middle and lower classes, women, and people of color were locked out of achieving a post-secondary education. Thelin recalled that the shift in student diversity of college enrollees did not change until federal laws were enacted and market forces demanded college degree attainment to be the baseline entry into the workforce.

Despite the enormous growth in college enrollment, the price of post-secondary education has skyrocketed immensely - even outpacing inflation, average salary increases, and average costs of living (Shambaugh \& Nunn, 2017). Zusman's (2005) research outlined the sizable shrinking of state funding for higher education as U.S. states have become "minority partners" in the colleges and universities that typically bear their names. This shift in funding has spurred the privatization of higher education. Furthermore, it has increased the gaps between access, success, and diversity. However, Zusman's research also identified a bevy of negative externalities. His research suggested that the increased reliance on part-time faculty threatens tenure and may harm the quality of higher education. Considering that higher education institutions are increasingly beholden to the demands of the market, Zusman goes on to demonstrate that institutions are pressured increasingly, to focus on enrollment in programs that promise tuition-paying students, high-paying jobs. As importantly, educational institutions tend to shift resources to programs that attract more external research grants.

Such factors drive the growing gap between the "haves" and the "have-nots" (Zusman, 2005). Institutions and students are forced to make choices that deleteriously impact underserved and non-traditional students, "including returning adults and those whose initial preparation precludes admission at other institutions, [who] may well be shut-out of traditionally open-door community colleges" (Zusman, 2005, p. 124). The collaboration between universities and industries further, contributes to a politicized commercialization that "may further shift research priorities toward more marketable areas in science and technology fields, distort traditional academic missions, and replace science dedicated to the public good with the "privatization of knowledge"' (Zusman, 2005, p. 127). Ultimately, Zusman questioned who will actually be able to attend college in the future, as enrollment has a particularly negative impact on those with lower income, those whose parents did not attend college, immigrants, and students of color.

Considering that the historical arc of access to higher education, for diverse students has slowly bent toward providing equal opportunities, generally, the existing academic curriculum and pedagogy have not been examined and changed as a means of realizing, either equity or equality. Understandably, the US college and university curricula were originally brought by the educated American colonists and Calvinist ministers who were influenced by the medieval English university (Bastedo, 2005). The early curriculum was designed for only two tracks-law or the clergy. In fact, not much has changed over the centuries. Bastedo (2005) indicated that, "The classical curriculum, while dynamic in some ways - through extracurricular lectures, literary societies, and the gradual adoption of new subjects-remained remarkably consistent for most of the colonial era and well into the nineteenth century" (p. 474). Minuscule changes have been made to the core curriculum. Indeed debates rage, for example, concerning the ideological 
clashes in history and sociology. This is despite, launching new fields and multidisciplinary students in contemporary higher education (Thelin, 2004).

In the next section, this article highlights some of the specific issues that diverse students face in higher education, namely the multiple aspects of The Imposter Syndrome. The ultimate purpose is to demonstrate that CBE can provide a culturally relevant and responsive pedagogy which may ameliorate the effects of The Imposter Syndrome, as well as reduce the negative impacts of other systems which contribute to the subpar educational attainment of diverse students.

\section{The Impostor Syndrome}

James (2017) has noted that educational attainment for diverse students is mired in racism, segregation, and hegemonic policies and practices encountered across and through various sectors of U.S. society. He further stated, that regarding college affordability and readiness, the existing systems have and continue to make college attendance and graduation challenging and extremely difficult for diverse students. Some such students, unfortunately, demonstrate characteristics which have been labelled as The Imposter Syndrome.

According to McGee (2017, p. 3), The Impostor Syndrome has six major tenets:

Firstly, The Impostor Cycle-confronting an achievement-related task leads to anxiety, self-doubt, and worry in the individual. Which in turn, leads to over-preparation, and/or procrastination. It is followed by accomplishment, a feeling of relief, the discounting of positive feedback, and further followed by perceptions of fraudulence, increased selfdoubt, depression and anxiety.

Secondly, The need to be special, to be the very best.

Thirdly, The Superwoman/Superman characteristics, including the urge to be perfect.

Fourthly, The fear of failure.

Fifthly, The denial of competence as well as discounting praise given by others.

Sixthly, The fear and guilt about success.

Simmons (2016) suggested that due to the diverse students' challenging life experiences and realities, that a reparative history instead of the mainstream history should be taught. To this end, she stated that: "A reparative history might name the inheritances of the Cold War militaryindustrial academic infrastructure, of technocratic feminism, of motivation psychology, of slavery...Repair tends to revolve around a desire to heal the self through the care of others" (p. 108). Simmons recognizes that many queer students and students of color, among others, live through forms of precariousness that challenge the institutions and their diversity optimisms (Simmons, 2016). Accordingly, post-secondary institutions should become the leading agents in teaching a form of reparative history_-particularly, through re-examining, re-conceptualizing, and re-imagining the formal curriculum and pedagogy. 


\section{Culturally Relevant Pedagogy (CRP)}

One of the primary means by which institutions can reimagine their curriculum and pedagogy in terms of, teaching a form of reparative history, is to introduce a culturally relevant pedagogy (CRP). Gloria Ladson-Billings coined the term and defined it as:

A pedagogy of oppression not unlike critical pedagogy but specifically committed to collective, not merely individual, empowerment. Culturally relevant pedagogy rests on three criteria or propositions: (a) students must experience academic success; (b) students must develop and/or maintain cultural competence; and (c) students must develop a critical consciousness through which they challenge the current status quo of the social order. (Ladson-Billings, 1995)

Brown-Jeffy and Cooper (2011) suggested that teaching about and interacting with diversity is vital in order to ameliorate the effects of cultural discontinuity. Furthermore, they emphasized the necessity of non-judgmental teachers who are inclusive. In order for such teachers to be effective facilitators of students' learning, the teachers recognize and accept the cultural backgrounds of their students. A culturally relevant pedagogy can address the sociohistorical patterns of schooling in the U.S. It recognizes how culture and race interact and further that the educational system is the primary pillar which supports that pattern.

In terms of the curricula, there is the necessity that the subject matter and resources incorporate more accurate content, and present more comprehensive portrayals of ethnic and racially diverse groups, and their lived experiences. As Gay (2016) aptly states: "This emphasis on 'teaching to' cultural diversity helps students acquire more accurate knowledge about the lives, cultures, contributions, experiences, and challenges of different ethnic and racial groups in U.S. society, knowledge that is often unrecognized or denigrated in conventional schooling" (p. 49).

Culturally relevant pedagogy can potentially redefine and reimagine the concept of safe spaces, in a way that makes the previously uncomfortable a part of a rigorously intellectual environment. An environment that "teaches out" ignorant, mental frameworks and conventional notions. It teaches against an environment which allows students to either consciously or unconsciously utilize "microaggressions." Robbins for example, indicated that "some universities' college students are also calling for safe spaces where they can be protected from ideas or words that might cause them discomfort but also allow them to feel safe around others who agree to abstain from criticizing or using microaggressions" (Robbins, 2016, p. 2). Microaggressions are brief, subtle, often unconscious, verbal slights or actions that convey hostile, derogatory, racist, sexist, homophobic, or other insults or messages of inferiority regarding others that become cumulative, over time (Robbins, 2016, p. 2).

\section{The Bridge between The Imposter Syndrome, CRP, and CBE}

As highlighted in the above review of the literature, the majority of diverse students often face an array of challenges in post-secondary education. However, the introduction of CBE fosters better engagement and academic outcomes for marginalized students. Another key tenet of CBE lies in its relevancy due to its more personalized nature. Despite the obvious benefits of saving time and money, and preventing academic failure, a key aspect of personalization has not 
been identified in the literature. If utilized in ways posited in this paper, CBE can cater to the unique emotional, psychosocial, and cultural needs of the individual. Potentially, personalization can curb issues stemming from The Imposter Syndrome, biased student assessments, irrelevant curricula content and content that does not include a restorative, reparative history (outlined earlier).

\section{Competency-Based Education (CBE): A Curriculum Solution}

Makulova, et al.'s (2015) definition of CBE is as follows:

"Competency-based approach" has been extended at the beginning of the XXI century in connection with discussions about problems and ways of modernization of the education. Innovative education-is not only a new way of teaching but also a new way of thinking. This education focuses not on the transfer of knowledge, which constantly outdates, but on mastering the core competencies that allow them to acquire knowledge on their own. (p. 183)

CBE provides a novel model as to how the curricula and pedagogy are manifested at the overall educational systems level. This is important to note as one considers the benefits CBE can have for traditionally underserved and diverse student populations. CBE measures learning outcomes rather than seat time/credit hours. Students have the ability to progress through coursework as soon as they can prove a mastery of the material-potentially, at a rate, far earlier than the end of a traditional semester. In fact, one can capitalize on one's previous work or school experiences and prior knowledge in order to progress through the course materials. If a student, however, requires additional support or time, he or she will work through the materials, by beginning at his or her current level and progressing at the individual's pace.

With the challenges that diverse students can confront, $\mathrm{CBE}$ has the potential to curb the effects of The Impostor Syndrome by allowing the students to follow a self-paced curriculum. Furthermore, a more holistic, individualized teaching-learning approach which considers the students' knowledge, skills, abilities and needs, may promote students' self-actualization.

Potentially, a CBE can ensure a culturally relevant curricula and pedagogy. Although the STEM (science, technology, engineering, and math) fields are quite straightforward, in practice, CBE has the potential to be transformative in the liberal arts as well as in the STEM fieldsparticularly, when history is involved in Sociology, Anthropology, Gender Studies, Ethnic Studies, Culture Studies, Psychology, History, etc.

This level of support can be somewhat ensured if the proper structure is established around the teaching and learning environment for the student. For example, assigning mentors to students offers salient resources for tending to the holistic needs of the students - both academically and personally (socially, emotionally, psychologically, etc., See Sheridan, Murdoch, \& Harder, 2015). This is significant especially when considering that college students can face unique forms of prejudice on campus - so much so, that diverse students are significantly less likely to be satisfied with their respective college environments and overall experience (ASHE Higher Education Report, 2015). The ASHE report delineates seven major themes from its research concerning, how diverse students' experiences are shaped by prejudice and racism - (1) racial hostility, (2) racial prejudice and stereotypes, (3) racial invisibility and 
silencing, (4) racial balkanization or segregation, (5) cultural conflict and dissonance, (6) contradictory cultural pressures, and (7) cultural marginalization and isolation. Unfortunately, these negative experiences apply to students, staff, and faculty. Furthermore, such experiences are also found in the curricula and the pedagogical practices of instructors (Sheridan, Murdoch, \& Harder, 2015).

Therefore, this paper asserts the plausibility and feasibility of CBE combating such negative aspects of college attendance for diverse students. Furthermore, CBE can possibly improve the success of these students through potential cost savings, curbing Impostor Syndrome influences, and mitigating the negative externalities of biased curricula and pedagogy. For demonstration purposes, the next section explores two plausible classroom assignments and suggests an alternative derived from CBE in order to curb some of the potential negative issues of the more traditional, and typical assignments.

\section{A Case in Point_-For the Humanities}

Education systems (elementary, secondary, and post-secondary) can introduce levels of cultural and nationalistic biases - biases that can distort a genuine assessment of student ability rather than assessing nationalistic/sociocultural indoctrination. Consequently, issues of political correctness and the notion of safe spaces can be violated for certain students. For example, if an educator wanted to assess students' abilities to compare historical events and explain how such events have shaped a region's evolution and as importantly, might influence future events, students might be given the following assignment. The assignment could inquire how the first president of the United States, George Washington, commanded a new country based on three historical events which benefited the North American continent. Such an assignment, however, be offensive and untenable for certain students in the class.

The assignment assumes the beneficence of George Washington. It limits the discussion to a mere recollection of isolated incidents. Indigenous or other American students of color could have an alternative perspective. They could argue that George Washington created more negative than positive impacts on the continent. Indigenous or other American students of color might explain: the genocide of Indigenous Americans, the devaluation and erasure of their culture, and the stealing of the land. Some students might speak about the capture, ownership, assault, and rape of African captives and shackle slavery. The students might state that such sanctioned actions are antithetical to notions of Washington being a positive force on the North American continent.

A traditional history assignment (outlined above) could breed severe tensions in some students' non-traditional responses and disrupt a content driven classroom environment. It might quell the salience of an otherwise enriched academic and educational environment. The traditionally underserved students could also fear reprisals for speaking in opposition to such an assignment. Tangentially, privileged students could offer seemingly unharmful commentary that in fact serves as "microaggression" rhetoric to other students within the classroom.

In the construction of the CBE inquiry, curricular biases can be avoided. If this assignment were presented as follows: "Describe the impact George Washington posed on the North American continent from the vantage point of at least three disparate groups of people residing on the continent, and provide support why you believe the impacts were either positive

Cultural and Pedagogical Inquiry, Summer 2019, 11(2), pp. 67-77

ISSN 1916-3460 @ 2019 University of Alberta

http://ejournals.library.ualberta.ca/index.php/cpi/index 
or negative from economic, cultural, global, and social standpoints." Markedly different types of responses could be generated. The restructuring of this assignment forces the students to utilize multiple perspectives and skill sets while not initially subscribing to culturally biased perspectives. To grapple with the assignment, the students would require in-depth, well researched knowledge of the events and circumstances surrounding Washington's leadership. They would also, demonstrate the abilities to apply the knowledge from various well documented sources and different viewpoints utilizing economic, social, global, and cultural lenses. Such a higher-order inquiry and discourse are central to long-term and lifelong student success. Contemporary captains of industry like Julie Sweet and Bill Gates claim that the top four skills of the future workforce are communication skills, a competitive spirit, a team-player mentality, and the ability to solve problems (Mello, 2017). At the very core, the idea of competence drives the ability to solve problems. Solving problems doesn't entail memorizing facts; rather, it relies on the ability of the individual to process and apply new knowledge in a manner that can solve problems in completely new situations. As importantly, the CBE assignment could trigger certain students, to deconstruct the notions of safe teaching and learning spaces.

\section{A Case in Point_-For the Sciences}

A simple assignment in the sciences could explore the sun and the speed of its rays. If an educator were trying to teach that [distance $=$ rate $\mathrm{x}$ time], one could ask how long it would take for the sun's rays to reach Earth by providing the student with the speed of light and the distance to the sun from the Earth. The students would be instructed to use mathematical computations to prove it. While this may lead to students being able to compute the mathematics, it fails to be relevant and provide a project-based format that leads to improved student engagement, efficiency, and production as aforementioned in the definition of CBE provided by the U.S Department of Education.

Conversely, an approach grounded in CBE could render much different results. For example, an instructor could present an assignment that could question: "What challenges would be present in receiving communication to Earth from a satellite orbiting around the sun whose job it is to inform Earth about an incoming asteroid? And, what implications could this have if all of the satellites around Earth stopped working and the satellite around the sun was the only remaining working satellite?" The students would be provided with the speed of light and Earth's distance from the sun as in the first example. Further, the students would be informed that satellites control our cell phones, GPS systems, and cable and internet in some instances.

This higher order level thinking assignment would be relevant to students' hypothetical well-being and the technologies that govern their lives. The core aspect of the assignment would yield that the communication gap between the sun and the Earth is about $81 / 2$ minutes. The students would be able to produce answers suggesting that the lone satellite could not facilitate useful communication on Earth; e.g., if one was having a phone conversation, it would take $81 / 2$ minutes to hear what was said and an additional $81 / 2$ minutes for a reply to be heard. Essentially, a true 17-minute communication gap would exist between the Earth and the sun-a seamless phone call would be impossible to conduct, television and internet signals would be 17 minutes late (communication from Earth to the satellite and back), and GPS systems could render 
someone a great distance away from their intended destination, as a result of the time and distance gap.

These types of practical real-life application assignments tend to the holistic learning needs of the student as expressed in the review of the literature. Therefore, efficient and targeted utilization of CBE offers a reparative and restorative history, creates a more open and safe learning spaces, and promotes academic success. In so doing, CBE quells issues pertaining to The Imposter Syndrome and microaggressions. It presents a culturally responsive and relevant curriculum for diverse students. Although this paper has focused on higher education, CBE can undoubtedly, be applied throughout the K-16 pipeline and beyond. CBE can set a new standard of learning to ensure that all people of all ages learn disciplinary content for its breadth and depth.

\section{Conclusion}

In practical terms, students can potentially reduce the cost of their education using the CBE model because it allows them to progress at their own pace - or ensure success if additional time is needed. Essentially, CBE presents unique opportunities to address the holistic needs of students through providing the financial, emotional, psychological, and academic supports required. Ultimately, $\mathrm{CBE}$ can be utilized for the collective benefit of all to promote inclusion and equity through exposure to different, new, and varying viewpoints from one's own.

A CBE teaching-learning environment can potentially, counteract and mitigate, the abilities of the American society to postulate, suggest and accept "alternative facts." Furthermore, in providing students with a more comprehensive curricula, with multiple viewpoints, and an unbiased pedagogy, educators can use CBE to promote the cause of social justice. In empowering students to realize humanity's collective symbiosis, students can shed their notions of "otherness". They can learn from their peers who come from different social, economic and cultural backgrounds and have different life experiences. In liberating the speech and contextualizing the unique lived experiences of everyone, students can genuinely learn and grow from one another. 


\section{References}

ASHE Higher Education Report. (2015). Racism and racial equity in higher education. Las Vegas: ASHE Higher Education Report.

Bastedo, M. (2005). Curriculum in higher education: The historical roots of contemporary issues. In P. Altbach, R. Berdhal, \& P. Gumport (Eds.), American higher education in the twenty-first century: Social, political, and economic challenges (pp. 462-485). Baltimore, Maryland: The Johns Hopkins University Press.

Brown-Jeffy, S., \& Cooper, J. (2011). Toward a Conceptual Framework of Culturally Relevant Pedagogy: An Overview of the Conceptual and Theoretical Literature. Teacher Education Quarterly, 65-84.

Duderstadt, J., \& Womack, F. (2003). Beyond the Crossroads. Baltimore: The Johns Hopkins University Press.

Gay, G. (2013). Teaching To and Through Cultural Diversity. Curriculum Inquiry, 48-70.

Hartlage, L. C., Lucas, T. L., \& Godwin, A. (1976). Culturally Biased and Culture-Fair Tests Correlated with School Performance in Culturally Disadvantaged Children. Journal of Clinical Psychology, 32(3), 658. Retrieved from:

https://wgu.idm.oclc.org/login?url=http://search.ebscohost.com/login.aspx?direct=true\&d $\underline{\mathrm{b}=e d b \& \mathrm{AN}=15844953 \& \text { site }=\text { eds-live \&scope }=\text { site }}$

James, A. M. (2017, January 31). Wayne State University Dissertations. Retrieved April 29, 2018, from Black Male Genocide: Sanctioned Segregation In American Policy: https://digitalcommons.wayne.edu/oa_dissertations/1712

Ladson-Billings, G. (1995). But That's Just Good Teaching! The Case for Culturally Relevant Pedagogy. Theory Into Practice, 34(3), 159-165. Retrieved from: http://www.jstor.org/stable/1476635

Makulova, A. T., Alimzhanova, G. M., Bekturganova, Z. M., Umirzakova, Z. A., Makulova, L. T., Karymbayeva, K. M., et al. (2015). Theory and Practice of Competency-Based Approach in Education. International Education Studies, 183-192.

McGee, R. (2017). The Impostor Syndrome [A.K.A. "Fake It Until You Make It"]: A Case Study. ResearchGate, 1-22.

Mello, T. (2017, August 25). The Top Four Soft Skills Any Employee Will Need To Become A Superstar. Retrieved April 29, 2018, from Forbes: https://www.forbes.com/sites/theyec/2017/08/25/the-top-four-soft-skills-any-employeewill-need-to-become-a-superstar/\#7eb99ee37d51

Robbins, S. (2016). From the Editor-Sticks and Stones: Trigger Warnings, Microaggressions, and Political Correctness. Journal of Social Work Education, 1-5. 
Sheridan, L., Murdoch, N., \& Harder, E. (2015). Assessing Mentoring Culture: Faculty and Staff Perceptions, Gaps, and Strengths. Canadian Journal of Higher Education, 423-439.

Simmons, D. (2016). Impostor Syndrome, A Reparative History. Engaging Science, Technology, and Society, 106-127.

Thelin, J. (2004). A History of American Higher Education. Baltimore: The Johns Hopkins University Press.

US Department of Education. (2018). U.S. Department of Education. Retrieved from: Competency-Based Learning or Personalized Learning: https://www.ed.gov/oiinews/competency-based-learning-or-personalized-learning

Zusman, A. (2005). Challenges Facing Higher Education in the Twenty-First Century. In P. Altbach, R. Berdahl, \& P. Gumport, American Higher Education in the Twenty-First Century: Social, Political, and Economic Challenges (pp. 115-160). Baltimore, Maryland: The Johns Hopkins University Press. 